ОБОГАЩЕНИЕ ПОЛЕЗНЫХ ИСКОПАЕМЫХ

DOI: 10.26730/1999-4125-2021-4-49-65

УДК $622.7 ; 622.73 / .75 ; 622.75 / .77$

\author{
АНТРАЦИТ. СРАВНЕНИЕ ТЕХНОЛОГИЙ ОБОГАЩЕНИЯ. МЕТОДЫ \\ ОЦЕНКИ ЭФФЕКТИВНОСТИ РАЗДЕЛЕНИЯ УГЛЕЙ И АНТРАЦИТОВ В \\ ГРАВИТАЦИОННЫХ АППАРАТАХ С ТЯЖЕЛОЙ СРЕДОЙ
}

\title{
ANTHRACITE. COMPARISON OF ENRICHMENT TECHNOLOGIES. METHODS FOR EVALUATING THE EFFICIENCY OF SEPARATION OF COALS AND ANTHRACITES IN GRAVITY APPARATUSES WITH HEAVY MEDIA
}

Удовицкий Владимир Иванович ${ }^{\mathbf{1}}$, доктор техн. наук, зав. кафедрой ОПИ, профессор, e-mail: uvi@kuzstu.ru

Vladimir I. Udovitsky ${ }^{1}$, D.Sc. in Engineering, Head of Department, Professor, KuzSTU.

Кирнарский Анатолий Семенович², доктор техн. наук e-mail: anatoliy.kirnarskyy @ed-mg.de Anatolij S. Kirnarski ${ }^{2}$, Dr. Sc. in Engineering. Корчевский Александр Николаевич ${ }^{3}$, кандидат техн. наук, зав. кафедрой ОПИ, доцент, e-mail: korchevskyial@mail.ru

Aleksandr N. Korchevskyi ${ }^{3}$, C.Sc. in Engineering, Head of Department, Ass. Professor, DonNTU.

Бегунов Артем Александрович ${ }^{1}$, аспирант, e-mail: begunovaa@rambler.ru

Artem A. Begunov ${ }^{1}$, Postgraduate Кандинский Владимир Александрович ${ }^{1}$, аспирант, e-mail: kandinsky@brent.eco Vladimir A. Kandinsky ${ }^{1}$, PhD student

Плотникова Лариса Николаевна ${ }^{1}$, аспирант, e-mail: plotnikovalorik@ mail.ru

Larisa N. Plotnikova ${ }^{1}$, Postgraduate

${ }^{1}$ Кузбасский государственный технический университет имени Т.Ф. Горбачева, 650000, Россия, г. Кемерово, ул. Весенняя, 28

${ }^{1}$ T.F. Gorbachev Kuzbass State Technical University, 28 street Vesennyaya, Kemerovo, 650000,

Russian Federation

${ }^{2}$ Инжиниринг Доберсек ГмбХ, Германия, Pastorenkamp 31, D-41169 Moenchengladbach Deutschland

${ }^{2}$ Engineering Dobersek GmbH, Pastorenkamp 31, D-41169 Moenchengladbach Deutschland

${ }^{3}$ Донецкий национальный технический университет, Донецкая Народная Республика, 283001, г. Донецк, ул.Артема, 58

${ }^{3}$ Donetsk National Technical University, Donetsk People's Republic, 283001, Donetsk, Artem st., 58

Аннотация:

Антрацит - высшая разновидность угля. Общие запасы антращита составляют 1\% от мировых 
запасов угля. Исследовань особенности технологических схем обогащения антращита на пяти обогатительных фабриках. Учитывая уникальность свойств антрацита и его относительно небольшие мировые запасы, возникает необходимость максимального извлечения полезных компонентов в готовую продукиию. Рассмотрены и проанализированы существующче методы оценки эффективности разделения каменных углей и антрацитов класса 13-100 (150) мм в гравитационных аппаратах. Предложен вероятностный метод расчета извлечения фракциий различной плотности в концентрат и отходы тяжелосредного сепаратора СКВП, позволяющий оченивать технологическую эффективность обогащения.

Ключевые слова: антрацит, гранулометрический состав, фракционный состав, обогащение угля, концентрат, отходы, зольность, методы оценки эффективности разделения углей.

Информация о статье: поступило в редакциию 05.05.2021

\section{Abstract:}

Anthracite is the highest type of coal. Total anthracite reserves account for $1 \%$ of the world's coal reserves. The features of technological schemes of anthracite enrichment at five processing plants are investigated. Given the unique properties of anthracite and its relatively small global reserves, there is a need to maximize the extraction of useful components in the finished product. The existing methods for evaluating the efficiency of separation of coal and anthracite of class 13-100 (150) mm in gravity apparatuses are considered and analyzed. A probabilistic method is proposed for calculating the extraction of fractions of different densities into the concentrate and waste of SKVP heavy-medium separator, which allows evaluating the technological efficiency of enrichment.

Keywords: anthracite, granulometric composition, fractional composition, coal enrichment, concentrate, waste, ash content, methods for evaluating the efficiency of coal separation.

Article info: received May 05, 2021

Антрацит - самый древний из ископаемых углей, уголь наиболее высокой степени углефикации (метаморфизма), обладает большой теплотворной способностью, высокой плотностью и высокой электропроводностью [10]. От других видов угля антрацит отличается высоким содержанием связанного углерода $(91 \div 98 \%)$, низким содержанием влаги, серы, летучих веществ, высокой удельной теплотой сгорания [12]. Мировые запасы антрацита составляют порядка 24 млрд т, в т.ч. в России - 14 млрд т. Общие запасы антрацита составляют $1 \%$ от мировых запасов угля. По объему запасов Россия находится на 1 месте, за ней следуют Китай, Украина и Вьетнам.

Отдельно следует выделить группу «Сибантрацит», крупнейший в России производитель металлургических углей, мировой лидер по поставкам высококачественного антрацита марки Ultra High Grade (UHG) Колыванского месторождения. Производственные мощности Группы «Сибантрацит» расположены в Новосибирской и Кемеровской областях.

Группа «Сибантрацит» добывает антрацит на месторождениях Горловского угольного бассейна. АО «Сибирский антрацит» и ООО «Разрез Восточный» разрабатывают 3 угольных разреза: «Колыванский», «Горловский» и «Восточный».

В настоящее время антрацит помимо использования в энергетике применяется в черной и цветной металлургии (термоантрацит, карбонизатор, науглероживатель, гидроантрацит, фильтрант), а также для производства адсорбентов, электродов (технический полуграфит), электрокорунда, микрофонного порошка. Антрациты используются в качестве заменителя кокса и коксовой мелочи в доменных печах при пылеугольном вдувании, в производстве агломератов железной руды, железорудных окатышей, электродов [10]. Требования к качеству антрацита предъявляются более высокие по сравнению с топливно-энергетическим использованием. Даже сравнительно небольшое ухудшение некоторых свойств антрацита часто отрицательно влияет на качество промышленной продукции.

Учитывая относительно небольшое количество запасов антрацита в мире и уникальные его свойства, постановка задач по эффективному и бережному использованию имеющихся месторождений, совершенствованию существующих и созданию новых технологий обогащения с максимальным извлечением полезных компонентов в концентрат для снижения потерь с отходами всегда актуальна.

Для решения указанных задач в статье рассматривается и анализируется опыт гравитационного, флотационного обогащения антрацитов Рурского, Донецкого, Кузнецкого, 
Горловского бассейнов и особо методы оценки эффективности разделения антрацитов и каменных углей крупных классов в гравитационных аппаратах с тяжелой средой.

\section{Технологии обогащения антрацитов}

Рассмотрим опыт обогащения антрацита на примере пяти углеобогатительных фабрик: Иббенбюрен (Германия), ГОФ «Вахрушевская» (Украина), ЦОФ «Гуковская» (Ростовская обл.), ОФ «Листвянская-2» (Новосибирская обл.), ОФ «Красногорская» (Кузбасс).

Обогатительная фабрика в г. Иббенбюрен (Германия), основана в 1925 г. (рис. 1). К 2018 г. на предприятии проведен ряд технических перевооружений для замены оборудования на более современное. На фабрике обогащается антрацит Рурского каменноугольного бассейна. Технология переработки заключается в следующем - рядовой уголь предварительно усредняется, разделяется на машинные классы, а затем обогащается тяжелосредной сепарацией, отсадкой и флотацией.

Статистика показывает, что за период 2015-2020 гг. объемы использования угля возросли более чем на $30 \%$. Очевидно, что такие темпы неизбежно приводят к росту числа отходов и некондиционных продуктов, образующихся в технологическом процессе добычи и обогащения сырья [1-4].

На сегодняшний день перспективным являются технологические подходы, которые рассматривают все некондиционные продукты, полупродукты и отходы как вторичные сырьевые ресурсы, способные повысить рентабельность производства за счет внедрения наилучших доступных технологий [5-8].

Необходимость сочетания целей охраны окружающей среды в промышленной деятельности, поиска подходящих технических возможностей и экономического обоснования с целью получения положительного эффекта приводит к расширению технологических подходов, предлагаемых для решения вышеобозначенных проблем, например [9-12]:

- использование угольных отходов в строительстве;

- выделение редкоземельных элементов;

- сжигание непосредственно высокозольного топлива;

- получение гранулированного и брикетированного топлива;

- термохимическая переработка с получением газообразного топлива.

Сочетание нескольких подходов может повысить эффективность переработки и позволит достичь синергетического эффекта [13].

За последние годы все активнее идет речь о необходимости замены классических технологий сжигания угля более экологически чистыми. Именно пиролиз и газификация рассматриваются как альтернативные решения по превращению твердого топлива в энергию. Перевод топлива в газообразную форму и последующее сжигание газа позволяет получать более высокую теплоту сгорания энергоносителя и значительно меньший ущерб окружающей природной среде $[14,15]$.

В широком смысле процессы газификации и пиролиза заключаются в деструктивном превращении (термическом разложении) органических соединений в углеводороды с меньшей молекулярной массой при воздействии высокой температуры, ограниченном доступе кислорода и присутствии водяного пара (газификация) или полностью отсутствующем доступе кислорода (пиролиз). Конечный результат зависит от выбранного направления проведения процесса и созданных условий в реакторе.

Для прогнозирования объема выделяющегося газа при термической переработке твердого топлива может быть использован показатель - выход летучих веществ, определяемый в рамках технического анализа. Данный показатель является важной характеристикой твердого топлива, поскольку с ним связан целый ряд свойств горючего, которые определяют пригодность для тех или иных целей и прежде всего пригодность топлива для термохимической переработки.

Формование исходной смеси методов окатывания предполагает создание исходной смеси органического связующего и наполнителя в виде угольных отходов различных фракций. Очевидным является необходимость изучения влияния процентного соотношения компонентов на выход летучих веществ. Помимо этого, важно определить граничные условия содержания 


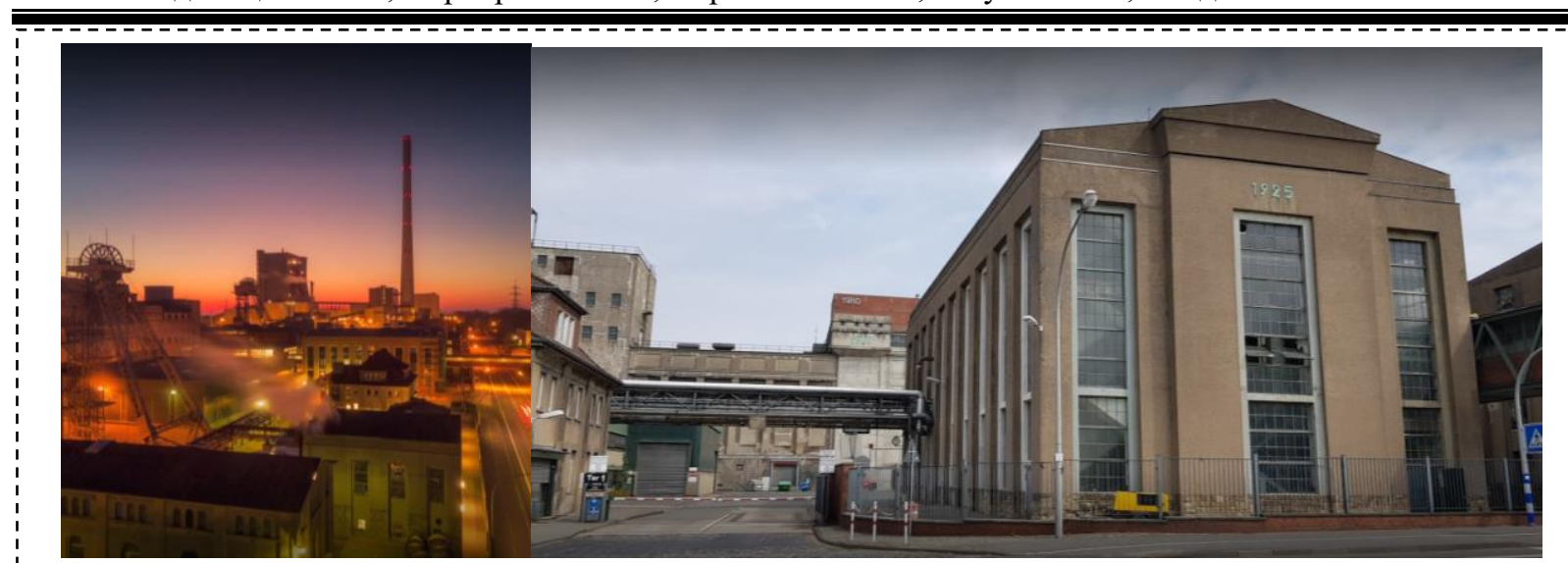

Puc. 1. RAG Anthrazit Ibbenbüren GmbH

Fig. 1. RAG Anthrazit Ibbenbüren $\mathrm{GmbH}$

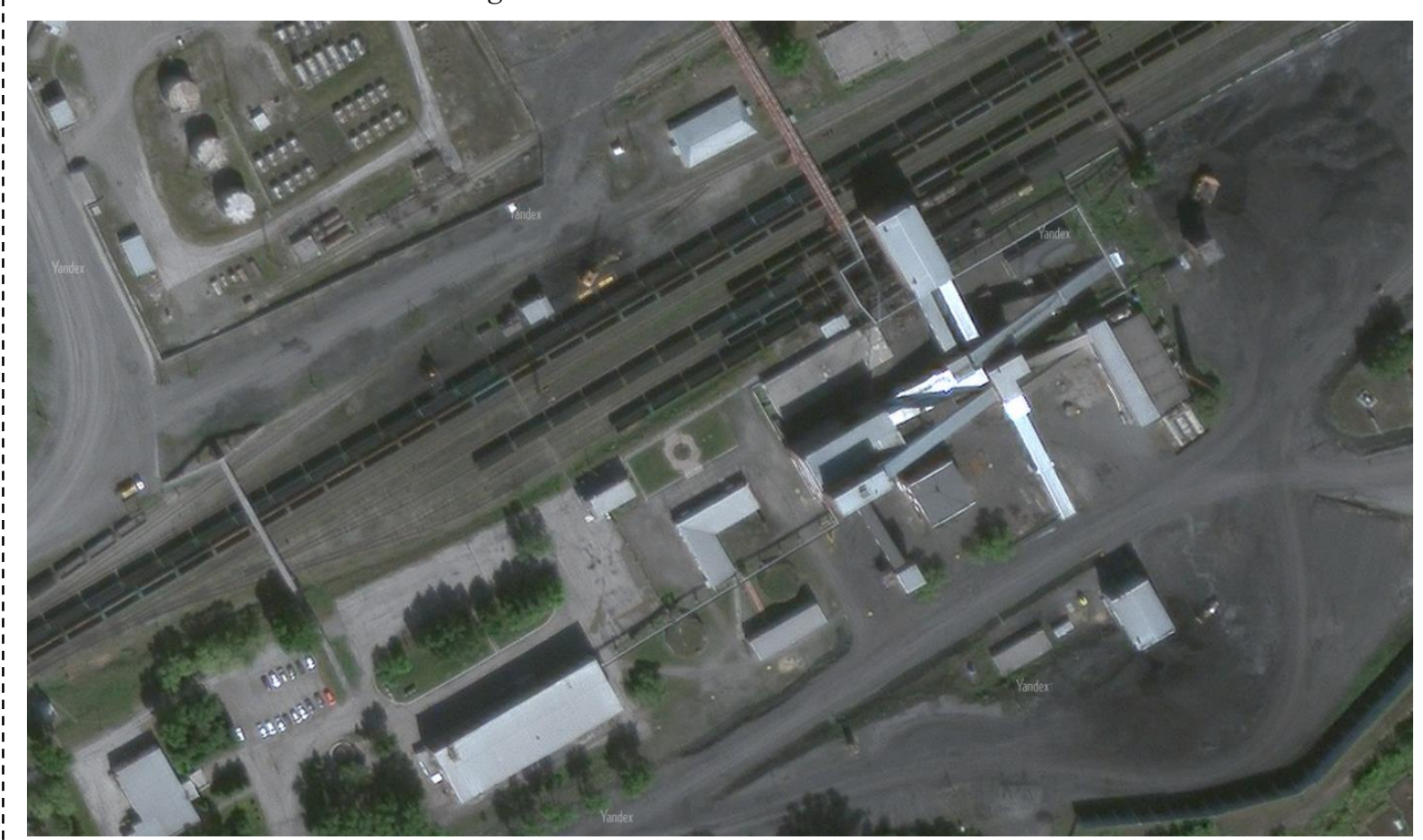

Рис. 2. Промплощадка ГОФ «Вахрушевская»

Fig. 2. Industrial site of the GOF «Vakhrushevskaya»

связующего вещества, при которых возможно формование гранулы достаточного фракционного размера и прочности для дальнейшей транспортировки и использования.

Таким образом, целью работы является определение состава угольных и органических отходов для получения высококалорийного газа методом газификации на основе углеродсодержащих отходов промышленных предприятий, в частности отходов угледобычи и переработки угля.

Для достижения данной цели были поставлены следующие задачи:

- провести технический анализ исходных угольных и органических отходов, применяемых в качестве наполнителя и связующего вещества соответственно;

- определить оптимальное соотношение угольные отходы / связующее для получения гранул заданного фракционного состава;

- изучить влияние процентного соотношения наполнитель/связующее на выход летучих веществ получаемых топливных гранул.

Водно-шламовая схема двухстадиальная с неглубоким осветлением шламовых вод при равновесном содержании твердой фазы в системе 20-40 г/л. На фабрике применяется термическая сушка. Флотационные отходы сгущаются в вертикальных отстойниках до 600 г/л, а затем вывозятся на породный отвал, где складируются совместно с породой тяжелосредных сепараторов и отсадочных машин. Крупный класс 40-80 мм обогащается на сепараторах типа 
Дрюбой в две стадии с выделением концентрата, промпродукта и отходов. Классы крупностью 10-40 мм и 1-10 мм обогащаются в пневматических отсадочных машинах Batac компании Humboldt Wedag с выделением кондиционного концентрата, промпродукта и отходов. Для обогащения класса 0-1 мм предусмотрены механические флотомашины фирмы «KHD» с вместимостью камер $6 \mathrm{~m}^{3}$ [13].

На ГОФ «Вахрушевская», построенной в 1955 г. (рис. 2), обогащается рядовой антрацит шахты им. В.В. Вахрушева и угли других предприятий, разгружаемые в ямы привозных углей. Существующая схема включает предварительную классификацию рядового угля на инерционных грохотах ГВИ $8 \times 2$ М по граничной крупности 25 мм, при этом надрешетный продукт крупностью более 25 мм подвергается дешламации и поступает на тяжелосредный сепаратор СКВ-20, а подрешетный продукт менее 25 мм направляется на два инерционных грохота, на которых удаляется шлам, а при необходимости выделяется сухой отсев (0-6 мм). После обесшламливания крупный и мелкий уголь разделяют по плотности соответственно тяжелосредной сепарацией и отсадкой. Средневероятное отклонение $E_{p m}$ тяжелосредного агрегата не превышает $40 \mathrm{\kappa} / \mathrm{M}^{3}$. Отсадочная машина ОМА-10 работает с погрешностью разделения менее 0,14 . Концентрат тяжелых сред и отсадки обезвоживается на инерционных грохотах. Магнетитовую суспензию регенирируют в две стадии посредством электромагнитных сепараторов ЭБМ-80/170П. Подрешетные воды собирают в зумпфе, а затем углесосом У900-90 подают на гидроциклоны диаметром 1000 мм, где шлам разделяют по крупности на зернистую и илистую части. Последняя самотеком поступает в пирамидальные отстойники общей площадью $40 \mathrm{~m}^{2}$. После осветления шламовых вод основную часть слива пирамидальных сгустителей используют в качестве оборотной воды, а малую часть сбрасывают в наружные илонакопители для восстановления. Сгущенный продукт гидроциклонов и пирамидальных отстойников, представленный зернистыми угольными шламами, без обогащения поступает на обезвоживание с помощью инерционного грохота ГИСЛ-42 и фильтрующей центрифуги ФВИ-1001Л, подрешетные воды и фугат которых сгущают в гидроциклоне диаметром 630 мм и обезвоживают на ленточном вакуум-фильтре ЛОП-15.

Генеральное опробование и изучение гранулометрических и фракционных характеристик обогащаемых углей показало, что исходная шихта на 46,54 \% представлена крупным углем более 13 мм, в то время как мелкого угля 1-13 мм и шлама 0-1 мм содержится соответственно 43,28 и $10,18 \%$. Зольность шихты составляет 32,44\%, показатель обогатимости крупного машинного класса более 13 мм равен 10,97\%. Это дает основание отнести его к категории труднообогатимого сырья, а мелкий машинный класс 1-13 мм имеет показатель обогатимости на уровне $9,76 \%$, что указывает на его среднюю обогатимость. Очень трудная обогатимость характерна для угольного шлама с показателем обогатимости не менее 17,71\%.

Исходя из заданного качества концентратов и обогатимости машинных классов, принято решение разделять крупный и мелкий классы в тяжелых средах, а шлам - на винтовой поверхности при условии предварительного обесшламливания по граничному зерну 0,04 мм. Класс 0-0,04 мм имеет очень трудную категорию обогатимости. Он на $77 \%$ состоит из породной фракции плотностью более 2100 кг $/ \mathrm{M}^{3}$ при содержании легкой фракции менее 1800 кг $/ \mathrm{M}^{3}$ всего 2\%, поэтому его выводят из схемы без обогащения. Водно-шламовая схема замкнутая. От применения флотации отказались из-за ее низкой эффективности для антрацитов данного месторождения, хотя ранее на ЦОФ «Нагольчанская» и ЦОФ «Свердловская» она была предусмотрена.

Центральная обогатительная фабрика «Гуковская», расположенная в Ростовской области, сдана в эксплуатацию в 1963 г. (рис. 3), обогащает угли Донецкого бассейна марки А. Антрацит, поступающий на фабрику, относится к средней категории обогатимости (показатель обогатимости, $T=7,5 \%$ ). Наименьшее количество «трудных» зерен при классификации на грохотах с ячейками сит 3 мм составляет 4,8\%, поэтому технология обогащения на фабрике имеет существенные отличия от общепринятой.

Рядовой уголь крупностью менее 100 мм подается на струнные грохоты ГСС-41, где происходит сухой рассев на классы более 3 и менее 3 мм. Надрешетный продукт грохотов подвергается классификации мокрым способом по этой же граничной крупности. 


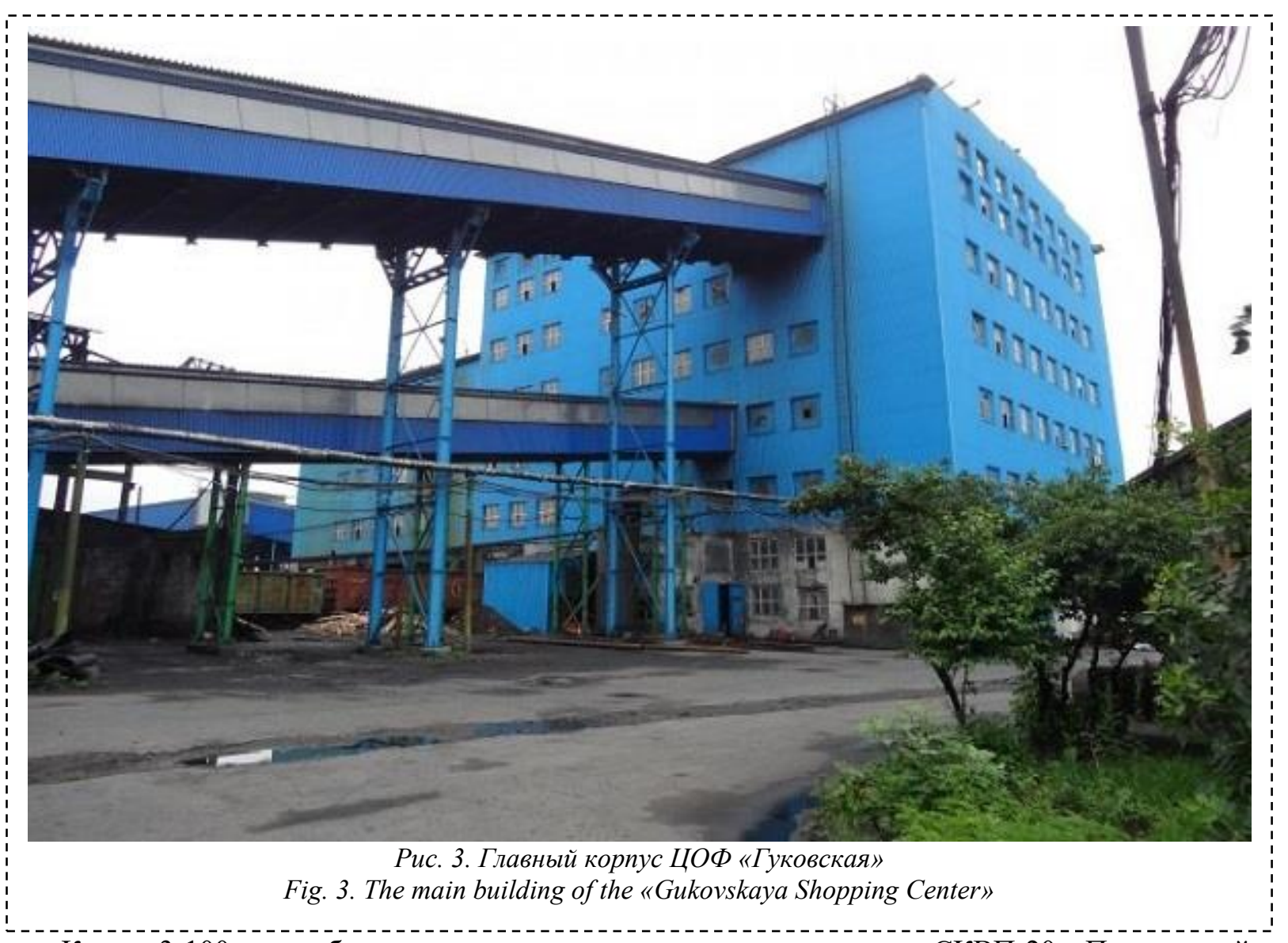

Класс 3-100 мм обогащается на тяжелосредном сепараторе СКВП-20. Полученный концентрат сортируется по крупности на товарные продукты, а отходы делятся на грохотах по граничной крупности 18 мм. Надрешетный продукт дробится до крупности менее 18 мм и направляется на переобогащение в тяжелосредный сепаратор СКВП-20. Это решение позволяет снизить потери легких фракций с отходами тяжелосредного обогащения. Шлам (менее 3 мм) обогащается на винтовых сепараторах МX-7.

Подрешетный продукт грохотов, обезвоживающих отходы винтовых сепараторов, слив гидроциклонов и шламовая вода из шламового бассейна направляются на сгущение в цилиндрический сгуститель. Слив сгустителя направляется в оборот, а сгущенный продукт закачивают в автоцистерны и перевозят на породный отвал для совместного складирования с породой, выделяемой с тяжелосредных и винтовых сепараторов $[14,18]$.

Обогатительная фабрика «Красногорская» обогащает антрацит Кузнецкого угольного бассейна, расположена в Кузбассе, сдана в эксплуатацию в 2002 г. Цех обогащения представлен на рисунке (рис. 4). Антрацит, поступающий на фабрику, обладает рядом особенностей: аномально низкий выход летучих, высокие калорийность и плотность, повышенная механическая твердость.

Указанные свойства связаны с метаморфизмом углей, вызванным внедрением силла диабазов. На данном месторождении это явление представлено куполообразным поднятием Сыркашинского силла диабаза мощностью от 60 до 160 м, которое является продолжением рядом расположенного Пихтовского месторождения диабазов. В пределах куполообразного поднятия плата в местах наибольшего сближения с силлом обнаружены угли с высоким значением удельного электрического сопротивления от 1500 до 1700 мкм на Ом $\times_{M}$, что сближает их с природными термоантрацитами. Кроме того, установлено увеличение содержания углерода до $96 \%$ и $2 \div 3$-х кратное снижение содержания водорода и кислорода [3].

Схемой фабрики предусмотрены следующие операции: рядовой уголь подвергается частичной классификации по крупности 25 мм с выделением сухого отсева. Крупный класс поступает на мокрую классификацию, где делится на классы 13-150 и 0-13 мм. Обогащение угля класса 13-150 мм производится в тяжелосредном сепараторе СКВП-20. 


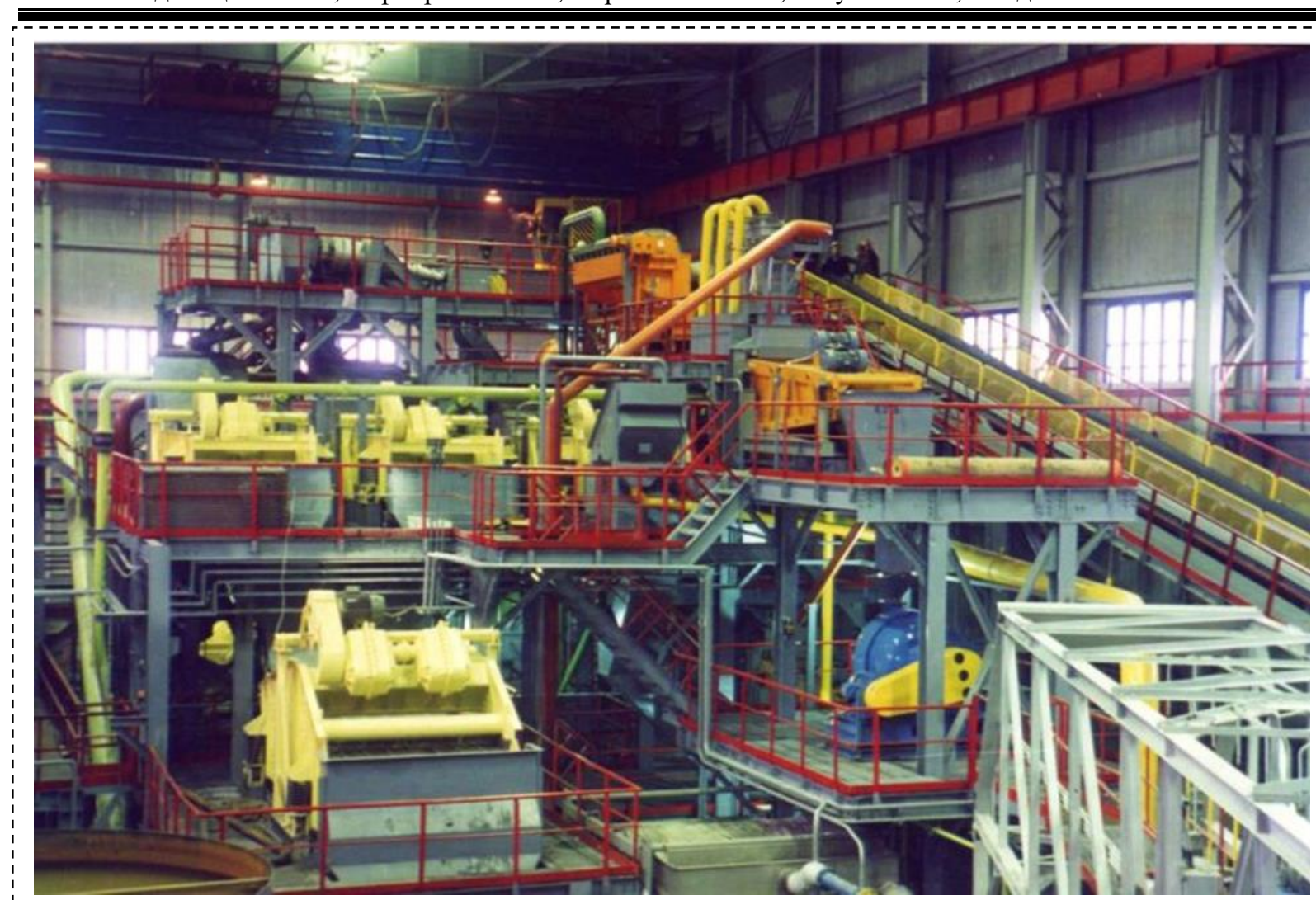

Рис. 4. Цех обогащения ОФ «Красногорская»

Fig. 4. Enrichment shop of the «Krasnogorskaya Oil Company»

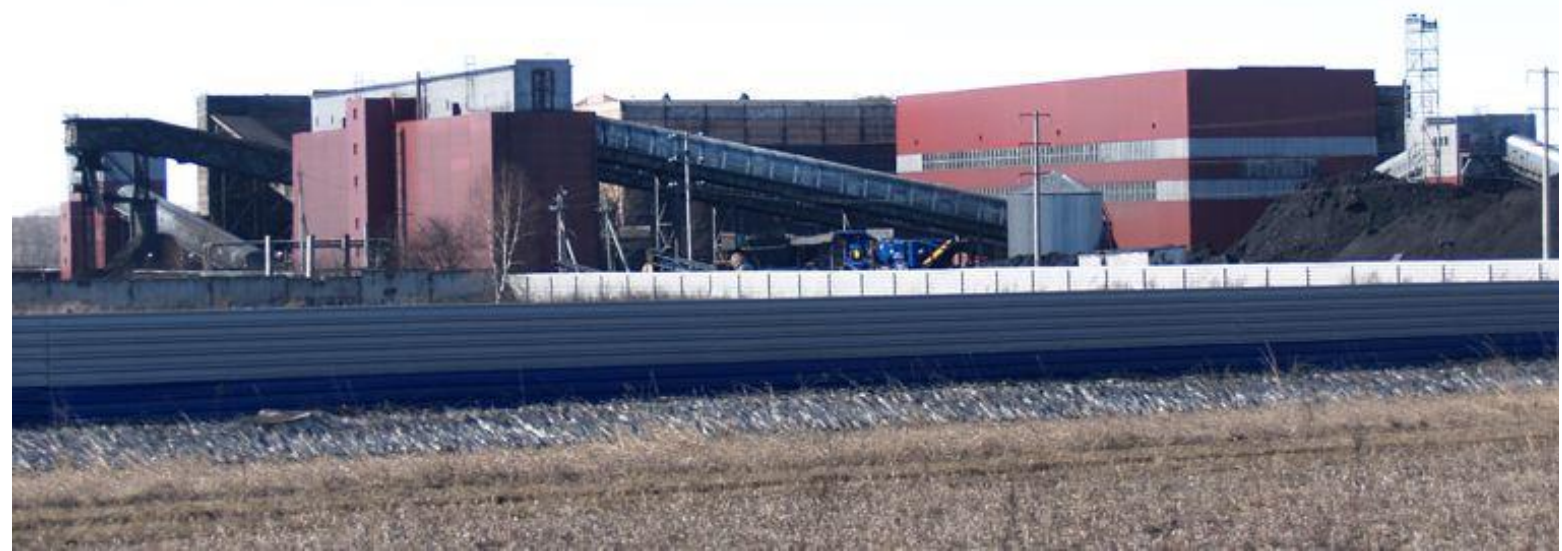

Рис. 5. ОФ «Листвянская-2»

Fig. 5. OF «Listvyanskaya-2»

Класс 0-13 мм подается для обесшламливания на дуговое сито и затем на грохот с размером ячейки сита 1 мм, надрешетный продукт которого обогащается в тяжелосредных гидроциклонах диаметром 610 мм. Классификация угля класса менее 1 мм происходит в классифицирующих гидроциклонах по граничному зерну разделения 0,1 мм, после чего пески класса 0,1-1 мм направляются на обогащение в спиральные сепараторы. Слив гидроциклонов сгущают в радиальном сгустителе. Сгущенный продукт обезвоживается на ленточных фильтрпрессах «Phoenix» и автосамосвалами вывозится для совместного складирования с отходами гравитационного обогащения. 
Таблица 1. Показатели работы обогатительных фабрик

Table 1. Performance indicators of processing plants

\begin{tabular}{|c|c|c|c|c|c|}
\hline Показатель & $\begin{array}{c}\text { ОФ } \\
\text { «Иббенбюрен» }\end{array}$ & $\begin{array}{c}\text { ГОФ } \\
\text { «Вахрушевская» }\end{array}$ & $\begin{array}{c}\text { ЦОФ } \\
\text { «Гуковская» }\end{array}$ & $\begin{array}{c}\text { ОФ } \\
\text { «Красногорская» }\end{array}$ & $\begin{array}{c}\text { ОФ } \\
\text { «Листвянс } \\
\text { кая-2» } \\
\end{array}$ \\
\hline $\begin{array}{l}\text { Год ввода в } \\
\text { эксплуатацию }\end{array}$ & 1925 & 1955 & 1963 & 2002 & 2007 \\
\hline $\begin{array}{l}\text { Производственная } \\
\text { мощность, } \\
\text { млн.т/год }\end{array}$ & 1,9 & 1,9 & 4,9 & 2,8 & 1,9 \\
\hline $\begin{array}{l}\text { Количество } \\
\text { машинных } \\
\text { классов } \\
\text { обогащения }\end{array}$ & $\begin{array}{c}4 \\
(40-80,10-40, \\
1-10,0-1)\end{array}$ & $\begin{array}{c}3 \\
(25-120,1-25, \\
0,04-1)\end{array}$ & $\begin{array}{c}2 \\
(3-100,0-3)\end{array}$ & $\begin{array}{c}3 \\
(13-150,1-13, \\
0,1-1)\end{array}$ & $\begin{array}{c}3 \\
(13-80,1- \\
13,0,15-1)\end{array}$ \\
\hline $\begin{array}{l}\text { Зольность } \\
\text { рядового угля, \% }\end{array}$ & $30,0-40,0$ & 32,3 & 38,0 & 22,1 & 13,0 \\
\hline $\begin{array}{l}\text { Выход } \\
\text { концентрата, \% }\end{array}$ & 50,0 & 62,7 & 65,5 & 52,3 & 93,7 \\
\hline $\begin{array}{l}\text { Зольность } \\
\text { концентрата, \% }\end{array}$ & $3,5-5,0$ & 7,7 & 15,9 & $12,0-13,0$ & $\begin{array}{c}4,5-6,0 \\
(12,0)\end{array}$ \\
\hline $\begin{array}{l}\text { Влажность } \\
\text { концентрата, \% }\end{array}$ & $\begin{array}{c}2,5-3,0 \\
\text { (термическая } \\
\text { сушка) } \\
\end{array}$ & 6,2 & 6,9 & $9,5-10,0$ & $9,0-13,0$ \\
\hline $\begin{array}{l}\text { Выход сухого } \\
\text { отсева, \% }\end{array}$ & 0 & 0 & 8,8 & 9,6 & 0 \\
\hline $\begin{array}{l}\text { Содержание } \\
\text { летучих, \% }\end{array}$ & 5,5 & $5,0-7,0$ & $3,6-4,2$ & $2,0-4,0$ & $2,0-4,0$ \\
\hline $\begin{array}{l}\text { Низшая теплота } \\
\text { сгорания } \\
\text { концентрата, } \\
\text { ккал/кг }\end{array}$ & $6800-6900$ & $6200-6500$ & $6250-6560$ & $6100-6200$ & $\begin{array}{c}6200- \\
6700\end{array}$ \\
\hline
\end{tabular}

Обогатительная фабрика «Листвянская-2》 (рис. 5) введена в эксплуатацию в 2007 г. для обогащения антрацита Горловского угольного бассейна в Новосибирской области. Технологическая схема обогатительной фабрики включает следующие операции: рядовой уголь крупностью менее 80 мм поступает на сухую классификацию по крупности 13 мм на грохотах Liwell. Подрешетный продукт грохота является готовой продукцией, концентратом марки АСШ.

Далее уголь класса 0-80 мм подается мокрую классификацию. Надрешетный продукт крупностью 13-80 мм поступает на обогащение в тяжелосредный сепаратор СКВП. 610 мм.

Обесшламленный класс 1-13 мм обогащается в тяжелосредном гидроциклоне диаметром

Материал класса 0-1 мм подается из зумпфа насосом на классификацию в гидроциклоны первой стадии, где происходит разделение на два класса: пески крупностью 0,15-1,0 мм и слив 0-0,15 мм. Пески поступают самотеком в распределительный бак трехзаходных спиральных сепараторов, а слив подается в радиальный сгуститель. Сгущенный продукт сгустителя насосами подается на камерные фильтр-прессы. Камерные фильтр-прессы обеспечивают получение кека влажностью 20-22\%.

Сводные данные по указанным обогатительным фабрикам представлены в таблице 1.

Проанализировав показатели работы обогатительных фабрик, можно отметить следующее:

1. Максимальная теплота сгорания (калорийность) достигнута на обогатительной фабрике «Иббенбюрен», что обусловлено низкозольными характеристиками угля, наличием термической сушки, при этом выход концентрата составляет всего 50,0\% при зольности исходного рядового угля до 40,0 \%. Обогащение производится по четырем машинным классам с глубиной до нуля за счет применения флотации.

2. Максимальный выход концентрата достигнут на фабрике «Листвянская-2», в основном за счет сухого отсева зольностью 12,0 \%, что обусловлено низкозольным рядовым углем, поступающим на обогащение. 
3. На ЦОФ «Гуковская» достигнуто максимальное извлечение полезного компонента в концентрат (зольность отходов 82,7\%), но при этом зольность концентрата, направляемого в готовую продукцию по классу 0-3 мм, составляет 23,1\% при выходе $23,3 \%$, что существенно снижает его востребованность на рынке. Следует также отметить, что наличие в схеме операции додрабливания крупного класса с раскрытием зерен и последующим переобогащением повышает извлечение горючей массы в готовую продукцию.

4. Для ГОФ «Вахрушевская» принята схема обогащения по трем машинным классам, при этом шлам 0-0,04 мм остается без обогащения в связи с низкой эффективностью флотации для углей данного месторождения.

5. Обогащаемые ОФ «Красногорская» антрациты очень трудной обогатимости, включающие в себя большое количество сростков и породных включений, не позволяют получать низкозольный концентрат. Благодаря таким свойствам концентрата, как низкий выход летучих, высокое содержание углерода, приближают его к термоантрацитам, поэтому концентрат зольностью 12,0-13,0\% пользуется спросом на рынке.

6. Использование тяжелосредного обогащения крупного класса является общим для всех представленных технологических схем, поэтому далее будут рассмотрены методы оценки эффективности разделения углей и антрацитов крупностью менее 100 (150) мм в колесных сепараторах.

\section{Эффективность разделения углей и антрацитов в гравитационных аппаратах}

Основное технологическое требование, предъявляемое к аппаратам, в которых осуществляется процесс гравитационного разделения, сводится к эффективному разделению исходного сырья с допустимой удельной производительностью.

Эффективность или точность разделения показывает, насколько близки практические результаты переработки к теоретически возможным, т.е. насколько точно фракции различной плотности распределились по конечным продуктам обогащения.

Для оценки технологической эффективности гравитационного разделения применяются различные аналитические, графические или графоаналитические критерии, основанные на характеристиках качества продуктов обогащения или их фракционном составе.

Широко применяется оценка точности разделения по фракционному составу продуктов, полученных в результате гравитационной переработки углей и антрацитов. Расслоение продуктов используется для экспресс-контроля при регулировке гравитационных аппаратов и оперативном управлении процессом разделения, а также для определения технологической эффективности действующих, новых или модернизированных машин. Оперативный контроль заключается в определении количества посторонних фракций в каждом продукте разделения: концентрате, промпродукте и отходах.

Сравнение эффективностей разделения в гравитационных аппаратах таким способом затруднено. Результаты опробования продуктов обогащения, полученные после расслоения каждого из них на три фракции (легкую, среднюю и тяжелую), будут представлены девятью показателями. Из них шесть характеризуют взаимозасоренность. При сравнении результатов переработки угля на двух аппаратах чаще бывает, что засорение концентрата в одной машине меньше, но потери легких фракций с породой больше, (возможны и другие варианты). В этом случае отдать предпочтение какому-либо аппарату трудно. Для сравнительной оценки правильнее определять суммарную засоренность всех продуктов

$\Sigma \alpha=\alpha_{\kappa}+\alpha_{n n}+\alpha_{n}$,

где $\alpha_{k}, \alpha_{n n}, \alpha_{n}-$ количество посторонних фракций в концентрате, промпродукте и породе в $\%$ к исходному углю.

Эффективность работы отсадочных машин по суммарному засорению конечных продуктов отсадки показана в таблице 2 .

Для сравнения методов гравитационного разделения пользуются среднегеометрическим показателем извлечения «своих» фракций в различные продукты. Этот показатель определяют по формуле 
Таблица 2. Оценка эффективности работы отсадочных машин

Table 2. Evaluation of the efficiency of jigging machines

\begin{tabular}{|c|c|}
\hline $\begin{array}{c}\text { Суммарное } \\
\text { засорение, } \% \text { к } \\
\text { исходному углю }\end{array}$ & Результаты расслоения \\
\hline$<4$ & Очень хорошие \\
\hline $4.0-8.0$ & Хорошие \\
\hline $14.0-14.0$ & Удовлетворительные \\
\hline$>20$ & Неудовлетворительные \\
\hline
\end{tabular}

$\varepsilon_{\phi . c p}=\left(\varepsilon_{1} \cdot \varepsilon_{2} \cdot \ldots \cdot \varepsilon_{n}\right)^{1 / n}$

где $\varepsilon_{\phi . ~ с р}-$ среднее извлечение фракций в продукты; $\varepsilon_{1}, \varepsilon_{2}, \ldots, \varepsilon_{n}-$ извлечение «своих» фракций в продукты;

$$
n \text { - количество продуктов. }
$$

Математические $r$ модели
оценки эффективности разделения
углей и антрацитов методами
вероятностного распределения

\section{фракций различных плотностей в продукты обогащения}

Кроме перечисленных выше способов определения эффективности разделения материала в гравитационных аппаратах в практике переработки широко применяется метод Тромпа, основанный на вероятностном распределении фракций различной плотности между продуктами гравитационного разделения. Параметрами оценки при этом методе является среднее вероятное отклонение, обозначаемое $E_{p m}$ (I'Ecart probable moyen) или $E_{p}[8,9]$.

Вероятное отклонение измеряется в единицах плотности на абсциссе кривой разделения

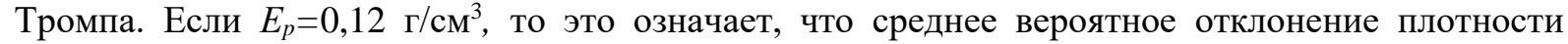
посторонних фракций в продуктах переработки от плотности разделения составляет 0,12.

Каждый гравитационный аппарат характеризуется своей кривой разделения, которая не зависит от качества исходного угля. Каждому типу аппарата, работающего в нормальных условиях, присуще свое определенное среднее вероятное отклонение, соответствующее кривой разделения данного аппарата.

Для нахождения $E_{p}$ действующей обогатительной машины необходимо:

1. Определить фракционный состав продуктов переработки: концентрата, промпродукта и породы. Для более точного построения кривой разделения фракционный состав необходимо определять по плотностям от 1,3 до 2,4 г/ $\mathrm{cm}^{3}$.

2. Рассчитать выходы продуктов переработки и в соответствии с ними выразить фракционный состав в процентах от исходного.

3. По фракционному составу продуктов обогащения рассчитать эквивалентный исходный материал, поступающий на данную операцию гравитационного разделения.

4. Определить разделительные числа для тяжелых продуктов двух плотностей разделения (для породы и микста).

5. Построить кривые Тромпа, по которым найти величину абсцисс для плотностей $\rho_{75}$ и $\rho_{25}$. По формуле вычислить значение среднего вероятного отклонения

$E_{p}=\left(\rho_{75}-\rho_{25}\right) / 2$.

Гравитационные аппараты для крупного угля дают всегда меньшее засорение продуктов разделения посторонними фракциями, чем машины мелкого угля.

Для машин с тяжелой средой величина $E_{p}$ изменяется незначительно в зависимости от плотности разделения. Для машин с водной средой $E_{p}$ возрастает пропорционально $\left(\rho_{p}-1\right)$.

$E_{p}=I\left(\rho_{p}-1\right)$,

где $I$ - коэффициент пропорциональности.

Этот коэффициент, предложенный П. Белюгу (Франция), называют коэффициентом погрешности или несовершенства (Imperfection).

Для контроля и оценки точности работы гравитационных машин с водной средой, кривая разделения которых подчиняется логарифмически нормальному закону, и величина $E_{p}$ значительно зависит от $\rho_{p}-1$, применяют коэффициент погрешности $I$.

Показатели $E_{p}$ и $I$ рекомендованы международной организацией по стандартизации $I S O$ в качестве критериев для оценки эффективности разделения минеральных комплексов в гравитационных полях и используются при прогнозировании практического баланса продуктов переработки. 
Согласно действующим в настоящее время в Российской Федерации нормативным документам [ВНТП 3-92] засорение продуктов обогащения каменных углей следует принимать в тяжелосредных сепараторах для крупности 13-100 (150) мм

$E_{p}=0.015 \cdot \rho_{p}+0.02, \Gamma / \mathrm{cm}^{3}$

Расчет выходов и зольностей продуктов переработки в гравитационных аппаратах осуществляют по формулам

$$
\begin{gathered}
\gamma=\sum_{i=1}^{n} \gamma_{i} \cdot \Phi\left(x_{i}\right) ; \\
A^{d}=\frac{\sum_{i=1}^{n} \gamma_{i} \cdot A_{i}^{d} \cdot \Phi\left(x_{i}\right)}{\sum_{i=1}^{n} \gamma_{i} \cdot \Phi\left(x_{i}\right)} ;
\end{gathered}
$$

где $n$ - количество фракций; $\Phi\left(x_{i}\right)$ - значение интеграла вероятностей Гаусса; $\gamma_{i}, A^{d}{ }_{i}-$ выход и зольность фракций; $x_{i}$ - отклонение средней плотности фракций $\rho_{c p}$ от намечаемой плотности разделения $\rho_{p}$ в тяжелосредных сепараторах СКВП

$$
x= \pm\left(\rho_{p}-\rho_{c p}\right) / E_{p} \cdot 0.675
$$

Практическое применение метода оценки эффективности разделения углей и антрацитов крупных классов в тяжелосредных сепараторах СКВП

При расчете технологических показателей гравитационного обогащения углей применяется интеграл вероятностей Гаусса, $\Phi(x)$

$$
\Phi(x)=\frac{1}{\sqrt{2 \pi}} \int_{-\infty}^{\infty} \exp \left(-\frac{x^{2}}{2}\right) d x ;
$$

\section{Условия и допущения, принятые при вычислении на ЭВМ значений интеграла вероятностей}

- Интеграл представляет площадь, заключенную между $-x,+x$ и общеизвестной кривой нормальной плотности распределения вероятностей. Полная площадь, лежащая под этой кривой, от $-\infty$ до $\infty$ равна 1 . Необходимо выбрать численный метод, который позволяет вычислять интеграл с точностью \pm 0.00003 . Важное значение имеет и скорость вычисления, т. к., например, определяя оптимальные плотности разделения для схемы ОФ «Распадская», при которых достигается максимальный выход суммарного концентрата, приходится прибегать к

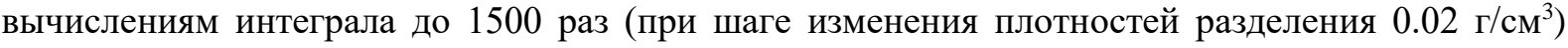
[17].

- Пределы интегрирования уменьшены в связи с тем, что вероятностные методы прогнозирования ожидаемых результатов гравитационного разделения углей [8] допускают при $x \leq-3.60, \quad \Phi(x)=0 ;$ при $x \geq 3.60 ; \quad \Phi(x)=1$, следовательно

$$
\Phi(x)=\frac{1}{\sqrt{2 \pi}} \int_{-3.6}^{3.6} \exp \left(-\frac{x^{2}}{2}\right) d x=1
$$

Площади, лежащие по обе стороны от оси ординат и ограниченные подынтегральной кривой и осью абсцисс, равны и составляют 0.5 , поэтому

для положительных $x$ можно применить формулу 
для отрицательных

$$
\Phi(x)=0.5+\frac{1}{\sqrt{2 \pi}} \int_{0}^{x} \exp \left(-\frac{x^{2}}{2}\right) d x
$$

$$
\Phi(x)=0.5-\frac{1}{\sqrt{2 \pi}} \int_{0}^{\operatorname{abs}(x)} \exp \left(-\frac{x^{2}}{2}\right) d x
$$

\section{Выбор метода интегрирования}

Рассмотрены следующие методы расчета интеграла вероятностей: прямоугольников; трапеций; Симпсона; Гаусса для двух, трех, четырех, пяти и шести точек; Вылегжанина, Монте-Карло и из степенного ряда. Методы сравнивались по точности и скорости вычисления. Для нахождения оптимального метода расчета значений интеграла вероятностей Гаусса на интервале изменения $x[0 ; 3.6]$ разработана отдельная программа, сравнивающая результаты работы всех описанных выше методов с табличными значениями интеграла вероятности Гаусса по величине среднеквадратического отклонения

Program Pr; VAR Tab: Array [1..11,0..360] of Real;Sum: Array [1..10] of Real; Nam: Array [1..11] of String; Nm1: Array [1..10] of String;

$n$ : String; sm : Real; $f$ : File of Real; $i, j$, nm: Integer; tb : File of Real;

BEGIN ClrScr; Nam[ 1]:= 'tab.gs'; Nam[2]:='tab.rec'; Nam[3]:= 'tab.tr';

Nam[ 4]:='tab.sim'; Nam[ 5]:='tab2.gs'; Nam[ 6]:='tab.gs3';Nam[ 7]:='tab4.gs'; Nam[ 8]:='tab.gs5'; Nam[ 9]:='tab6.gs';Nam[10]:='tab.stp'; am[11]:='tab.wig';

Nm1[ 1]:='Прямоугольников'; Nm1[ 2]:='Трапециий';Nm1[ 3]:='Симпсона'; Nm1[ 4]:='Гaycca 2';Nm1[ 5]:='Taycca 3'; Nm1[ 6]:='Гaycca 4';

Nm1[ 7]:='Гaycca 5'; Nm1[ 8]:='Гаyсcа 6';Nm1[ 9]:='Степенной ряд'; Nm1[10]:='Bылегжанина';for $j:=1$ to 11 do begin Assign(f, Nam[j] );

$\operatorname{ReSet}(f)$; for $i:=0$ to 360 do $\operatorname{Read}(f, \operatorname{Tab}[j, i])$; Close $(f)$ end;

for $j:=2$ to 11 do for $i:=0$ to 360 do $\operatorname{Tab}[j, i]:=\operatorname{sqr}(\operatorname{Tab}[j, i]-a b[1, i] * 0.0001)$;

for $j:=1$ to 10 do Sum[j]:=0; for $i:=0$ to 360 do for $j:=1$ to 10 do

Sum $[j]:=\operatorname{Sum}[j]+\operatorname{Tab}[j+1, i]$; for $j:=1$ to 10 do $\operatorname{Sum}[j]:=\operatorname{Sum}[j] / 361$;

Assign( $t b$, 'tab.pgr' ); ReSet( $t b) ;$ for $j:=1$ to 10 do

begin Sum[j]:=Sum[j]*1e8; Write(tb,Sum $[j]$ ); Sum $[j]:=S u m[j] / 1 e 8 ;$

end;Close ( $t b$ );for $i:=1$ to 10 do WriteLn( Nm1[i], Sum[i]*1e8:20:14 );

ReadLn; END.

Лучшим оказался метод вычисления интеграла Гаусса из степенного ряда, текст программы

Program IntGauss;

USES CRT;

VAR $i$ : Integer; $x, y:$ Real; Tst : Array [0..365] of Real; fl : File of Real;

PROCEDURE Gauss;

var $g x, g 4, g 5, g 6, g 7, g 15, x a b s:$ real;

begin $g x:=x^{*} x ; \quad x a b s:=a b s(x) ;$ if $a b s(x)>1.2$ then begin if $a b s(x)>2.9$ then begin if abs $(x)>3.6$ then $y:=0.5$ else begin $g 15:=1 / g x$;

$y:=0.5-0.398942 * 1 / \exp (g x / 2) / x a b s *(1-g 15 *(1-g 15 *(3-g 15 *(15-g 15 * 105))))$;

end end else begin $y:=1 ; g 4:=1 ; g 5:=0 ; g 6:=1$; repeat $g 5:=g 5+1 ; g 6:=g 6+2$;

$g 4:=-g 4 * g x /(2 * g 5) ; \quad g 7:=g 4 / g 6 ; \quad y:=y+g 7 ;$ until abs $(g 7)<0.00003 ; y:=0.398942 * x a b s * y$ end

end else $y:=0.398942 * x a b s *(0.99999774-g x *(0.16659433-g x *(0.024638310-g x * 0.0023974867)))$;

if $x<0$ then $y:=0.5-y$ else $y:=0.5+y$; end;

BEGIN for $i:=0$ to 360 do begin $x:=i * 0.01 ; \operatorname{GAUSS} ; \operatorname{WriteLn}(x: 5: 2, y: 8: 4)$;

Tst [i]:=y; end; End. 


\begin{tabular}{|c|c|c|c|c|c|c|c|c|c|c|c|}
\hline$t$ & $\Phi(t)$ & $\Phi(t) E x c$ & $\Phi(t) P a s$ & $t$ & $\Phi(t)$ & $\Phi(t) E x c$ & $\Phi(t) P a s$ & $t$ & $\Phi(t)$ & $\Phi(t) E x c$ & $\Phi(t) P a s$ \\
\hline 0 & 0,50000 & 0,50000 & 0,50000 & 1,33 & 0,90824 & 0,90824 & 0,90824 & 2,66 & 0,99610 & 0,99609 & 0,99609 \\
\hline 0,01 & 0,50399 & 0,50399 & 0,50399 & 1,34 & 0,90988 & 0,90988 & 0,90988 & 2,67 & 0,99621 & 0,99621 & 0,99621 \\
\hline 0,02 & 0,50798 & 0,50798 & 0,50798 & 1,35 & 0,91149 & 0,91149 & 0,91149 & 2,68 & 0,99632 & 0,99632 & 0,99632 \\
\hline 0,03 & 0,51197 & 0,51197 & 0,51197 & 1,36 & 0,91309 & 0,91309 & 0,91308 & 2,69 & 0,99643 & 0,99643 & 0,99643 \\
\hline 0,04 & 0,51596 & 0,51595 & 0,51595 & 1,37 & 0,91466 & 0,91466 & 0,91466 & 2,7 & 0,99654 & 0,99653 & 0,99653 \\
\hline 0,05 & 0,51994 & 0,51994 & 0,51994 & 1,38 & 0,91621 & 0,91621 & 0,91621 & 2,71 & 0,99664 & 0,99664 & 0,99664 \\
\hline 0,06 & 0,52392 & 0,52392 & 0,52392 & 1,39 & 0,91774 & 0,91774 & 0,91774 & 2,72 & 0,99674 & 0,99674 & 0,99674 \\
\hline 0,07 & 0,52791 & 0,52790 & 0,52790 & 1,4 & 0,91925 & 0,91924 & 0,91924 & 2,73 & 0,99684 & 0,99683 & 0,99683 \\
\hline 0,08 & 0,53188 & 0,53188 & 0,53188 & 1,41 & 0,92073 & 0,92073 & 0,92073 & 2,74 & 0,99693 & 0,99693 & 0,99693 \\
\hline 0,09 & 0,53586 & 0,53586 & 0,53586 & 1,42 & 0,92220 & 0,92220 & 0,92220 & 2,75 & 0,99702 & 0,99702 & 0,99702 \\
\hline 0,1 & 0,53983 & 0,53983 & 0,53983 & 1,43 & 0,92364 & 0,92364 & 0,92364 & 2,76 & 0,99711 & 0,99711 & 0,99711 \\
\hline 0,11 & 0,54380 & 0,54380 & 0,54380 & 1,44 & 0,92507 & 0,92507 & 0,92507 & 2,77 & 0,99720 & 0,99720 & 0,99720 \\
\hline 0,12 & 0,54776 & 0,54776 & 0,54776 & 1,45 & 0,92647 & 0,92647 & 0,92647 & 2,78 & 0,99728 & 0,99728 & 0,99728 \\
\hline
\end{tabular}

Сравнение точности вычисления интеграла Гаусса в Microsoft Excel и Turbo Pascal

В настоящее время возникла необходимость рассчитывать извлечение фракций в продукты обогащения на основе вероятностных методов с большей точностью. Для решения указанной задачи использовались Microsoft Excel и Turbo Pascal.

В Microsoft Excel есть функция НОРМСТРАCП(z), которая возвращает стандартное нормальное интегральное распределение. Это распределение имеет среднее, равное нулю, и стандартное отклонение, равное единице. Данная функция используется вместо таблицы площадей стандартной нормальной кривой.

Синтаксис НОРМСТРАСП(z), где $z$ - значение, для которого строится распределение.

Замечания:

Если $z$ не является числом, функция НОРМСТРАСП возвращает значение ошибки \#ЗНАЧ!.

Уравнение плотности стандартного нормального распределения имеет следующий вид:

$$
f(z)=\frac{1}{\sqrt{2 \pi}} e^{-\frac{z^{2}}{2}}
$$

Для решения этой же задачи в Turbo Pascal, воспользуемся программой, текст которой представлен выше, установив точность $a b s(g 7)<0.0000001$.

Результаты расчета показаны во фрагменте таблицы 3 (полный текст таблицы представлен в публикации [15]), где $\boldsymbol{t}$ - намечаемая плотность разделения, $\boldsymbol{\Phi}(\boldsymbol{t})$ - табличное значение интеграла Гаусса, $\boldsymbol{\Phi}(\boldsymbol{t}) \boldsymbol{E} \boldsymbol{x \boldsymbol { c }}$ - значения интеграла, рассчитанные с помощью электронных таблиц Excel, $\boldsymbol{\Phi}(\boldsymbol{t}) \boldsymbol{P a s}$ - значения интеграла, рассчитанные в Turbo Pascal.

Среднеквадратическое отклонение для функции $\Phi(x)$, рассчитанное с помощью Excel в диапазоне изменения аргумента от 0 до 3,83 с шагом 0.01, составило 0,00005001, в Turbo Pascal - 0,00005030. Таким образом, оба метода имеют, практически, одинаковую погрешность и 
Таблица 4а. Извлечение фракций в концентрат тяжелосредного сепаратора СКВП для класса 13 100(150) мм

Table 4a. Extraction of fractions in the concentrate of the heavy-medium separator SKVP for class 13-100 (150) $\mathrm{mm}$

\begin{tabular}{|c|c|c|c|c|c|c|c|c|c|c|c|c|c|}
\hline \multirow{2}{*}{$\rho_{\mathrm{p}}$} & \multicolumn{6}{|c|}{ Извлечение при средних плотностях фракций } & \multirow{2}{*}{$\rho_{\mathrm{p}}$} & \multicolumn{6}{|c|}{ Извлечение при средних плотностях фракций } \\
\hline & 1,25 & 1,35 & 1,45 & 1,55 & 1,70 & 2,20 & & 1,25 & 1,35 & 1,45 & 1,55 & 1,70 & 2,20 \\
\hline 1,20 & 18,72 & 0,39 & م 00 & 0,00 & 0,00 & 0,00 & 1,60 & 100,0 & 99,99 & 98,93 & 77,85 & 6,25 & 0,00 \\
\hline 1,21 & 23,96 & 0,66 & 0,00 & 0,00 & 0,00 & 0,00 & 1,61 & 100,0 & 100,0 & 99,28 & 82,05 & 8,44 & 0,00 \\
\hline 1,22 & 29,85 & 1,10 & 0,00 & 0,00 & 0,00 & 0,00 & 1,62 & 100,0 & 100,0 & 99,52 & 85,69 & 11,14 & 0,00 \\
\hline 1,23 & 36,28 & 1,76 & 0,01 & 0,00 & 0,00 & 0,00 & 1,63 & 100,0 & 100,0 & 99,69 & 88,78 & 14,39 & 0,00 \\
\hline 1,24 & 43,06 & 2,72 & 0,01 & 0,00 & 0,00 & 0,00 & 1,64 & 100,0 & 100,0 & 99,80 & 91,34 & 18,19 & 0,00 \\
\hline 1,25 & 50,00 & 4,08 & 0,02 & 0,00 & 0,00 & 0,00 & 1,65 & 100,0 & 100,0 & 99,87 & 93,43 & 22,54 & 0,00 \\
\hline 1,26 & 56,89 & 5,92 & 0,05 & 0,00 & 0,00 & 0,00 & 1,66 & 100,0 & 100,0 & 99,92 & 95,09 & 27,38 & 0,00 \\
\hline 1,27 & 63,52 & 8,34 & 0,09 & 0,00 & 0,00 & 0,00 & 1,67 & 100,0 & 100,0 & 99,95 & 96,39 & 32,65 & 0,00 \\
\hline 1,28 & 69,73 & 11,40 & 0,17 & 0,00 & 0,00 & 0,00 & 1,68 & 100,0 & 100,0 & 99,97 & 97,39 & 38,26 & 0,00 \\
\hline 1,29 & 75,37 & 15,17 & 0,30 & 0,00 & 0,00 & 0,00 & 1,69 & 100,0 & 100,0 & 99,98 & 98,14 & 44,08 & 0,00 \\
\hline 1,30 & 80,36 & 19,64 & 0,52 & 0,00 & 0,00 & 0,00 & 1,70 & 100,0 & 100,0 & 99,99 & 98,70 & 50,00 & 0,00 \\
\hline 1,31 & 84,65 & 24,79 & 0,86 & 0,00 & 0,00 & 0,00 & 1,71 & 100,0 & 100,0 & 99,99 & 99,10 & 55,88 & 0,00 \\
\hline 1,32 & 88,24 & 30,54 & 1,37 & 0,00 & 0,00 & 0,00 & 1,72 & 100,0 & 100,0 & 100,0 & 99,39 & 61,59 & 0,00 \\
\hline 1,33 & 91,18 & 36,77 & 2,13 & 0,01 & 0,00 & 0,00 & 1,73 & 100,0 & 100,0 & 100,0 & 99,59 & 67,03 & 0,00 \\
\hline 1,34 & 93,51 & 43,32 & 3,20 & 0,02 & 0,00 & 0,00 & 1,74 & 100,0 & 100,0 & 100,0 & 99,73 & 72,10 & 0,00 \\
\hline 1,35 & 95,32 & 50,00 & 4,68 & 0,04 & 0,00 & 0,00 & 1,75 & 100,0 & 100,0 & 100,0 & 99,82 & 76,72 & 0,00 \\
\hline 1,36 & 96,70 & 56,63 & 6,63 & 0,08 & 0,00 & 0,00 & 1,76 & 100,0 & 100,0 & 100,0 & 99,89 & 80,86 & 0,00 \\
\hline 1,37 & 97,71 & 63,04 & 9,15 & 0,14 & 0,00 & 0,00 & 1,77 & 100,0 & 100,0 & 100,0 & 99,93 & 84,50 & 0,00 \\
\hline 1,38 & 98,45 & 69,06 & 12,28 & 0,24 & 0,00 & 0,00 & 1,78 & 100,0 & 100,0 & 100,0 & 99,96 & 87,62 & 0,00 \\
\hline 1,39 & 98,96 & 74,57 & 16,07 & 0,41 & 0,00 & 0,00 & 1,79 & 100,0 & 100,0 & 100,0 & 99,97 & 90,26 & 0,00 \\
\hline 1,40 & 99,32 & 79,48 & 21 & 0,68 & 0 , & 0,00 & 1,80 & 0 & 100,0 & 0 & 9 & 92,45 & 00 \\
\hline 1,41 & 99,57 & 83,75 & 25,59 & 1,08 & 0,00 & 0,00 & 1,81 & 100,0 & 100,0 & 100,0 & 99,99 & 94,23 & 0,00 \\
\hline 1,42 & 99,73 & 87,37 & 3 & 8 & 0 , & 0 & 1,82 & 0 & 0 & 100,0 & 9 & 95,66 & 00 \\
\hline 1,43 & 99,83 & 90,37 & 37,23 & 2,53 & 0,00 & 0,00 & 1,83 & 100,0 & 100,0 & 100,0 & 100,0 & 96,78 & 0,00 \\
\hline 1,44 & 99,90 & 92,79 & 43,56 & 3,71 & 0,00 & 0,00 & 1,84 & 100,0 & 100,0 & 100,0 & 100,0 & 97,64 & 0,00 \\
\hline 1,45 & 99,94 & 94,70 & 50,0 & 5,30 & 0,0 & 0,00 & 1,85 & 100,0 & 100,0 & 11 & 100,0 & 98, & 0,00 \\
\hline 1,46 & 99,96 & 96,18 & 56,40 & 7,35 & 0,01 & 0,00 & 1,86 & 100,0 & 100,0 & 100,0 & 100,0 & 98,79 & 0,00 \\
\hline 1,47 & 99,98 & 97,30 & 62,59 & 5 & 0,01 & 0,00 & 1,87 & 100,0 & 100,0 & 100,0 & 100,0 & 95, & 0,00 \\
\hline 1,48 & 99,99 & 98,12 & 68,43 & 13,14 & 0,02 & 0,00 & 1,88 & 100,0 & 100,0 & 100,0 & 100,0 & 99,41 & 0,00 \\
\hline 1,49 & 99,99 & 98,72 & 73,81 & 16,95 & 0,04 & 0,00 & 1,89 & 100,0 & 100,0 & 100,0 & 100,0 & 99,60 & 0,00 \\
\hline 1,50 & 100,0 & 99,14 & 78,64 & 21,36 & 0,07 & 0,00 & 1,90 & 100,0 & 100,0 & 100,0 & 100,0 & 99,73 & 0,00 \\
\hline 1,51 & 100,0 & 99,43 & 82,88 & 26,33 & 0,13 & 0,00 & 1,91 & 100,0 & 100,0 & 100,0 & 100,0 & 99,82 & 0,00 \\
\hline 1,52 & 100,0 & 99,63 & 86,52 & 31,81 & 0,23 & 0,00 & 1,92 & 100,0 & 100,0 & 100,0 & 100,0 & 99 & 0,01 \\
\hline 1,53 & 100,0 & 99,77 & 89,57 & 37,66 & 0,38 & 0,00 & 1,93 & 100,0 & 100,0 & 100,0 & 100,0 & 99,92 & 0,01 \\
\hline 1,54 & 100,0 & 99,85 & 92,07 & 43,78 & 0,61 & 0,00 & 1,94 & 100,0 & 100,0 & 100,0 & 100,0 & 99,95 & 0,02 \\
\hline 1,55 & 100,0 & 99,91 & 94,07 & 50,00 & 0,96 & 0,00 & 1,95 & 100,0 & 100,0 & 100,0 & 100,0 & 99,97 & 0,03 \\
\hline 1,56 & 100,0 & 99,95 & 95,64 & 56,18 & 1,47 & 0,00 & 1,96 & 100,0 & 100,0 & 100,0 & 100,0 & 99,98 & 0,05 \\
\hline 1,57 & 100,0 & 99,97 & 96,86 & 62,17 & 2,20 & 0,00 & 1,97 & 100,0 & 100,0 & 100,0 & 100,0 & 99,99 & 0,09 \\
\hline 1,58 & 100,0 & 99,98 & 97,77 & 67,85 & 3,19 & 0,00 & 1,98 & 100,0 & 100,0 & 100,0 & 100,0 & 99,99 & 0,14 \\
\hline 1,59 & 100,0 & 99,99 & 98,44 & 73,10 & 4,52 & 0,00 & 1,99 & 100,0 & 100,0 & 100,0 & 100,0 & 100,0 & 0,22 \\
\hline
\end{tabular}


Таблица 4b. Извлечение фракций в отходы тяжелосредного сепаратора СКВП для класса 13-100(150)

мM

Table 4b. Extraction of fractions in the waste of the heavy-medium separator SKVP for class 13-100 (150) mm

\begin{tabular}{l|l||l}
\hline & Извлечение при средних плотностях фракиций & Извлечение при средних плотностях фракциий
\end{tabular}

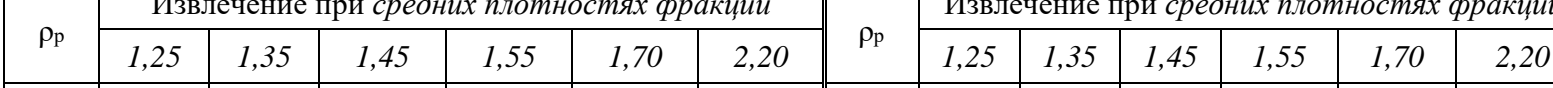

\begin{tabular}{|l|l|l|l|l|l|l|l|l|l|l|l|l|l|}
\hline 1,20 & 81,28 & 99,61 & 100,0 & 100,0 & 100,0 & 100,0 & 1,60 & 0,00 & 0,01 & 1,07 & 22,15 & 93,75 & 100,0 \\
\hline
\end{tabular}

\begin{tabular}{|l|l|l|l|l|l|l|l|l|l|l|l|l|l|l|}
\hline 1,21 & 76,04 & 99,34 & 100,0 & 100,0 & 100,0 & 100,0 & 1,61 & 0,00 & 0,00 & 0,72 & 17,95 & 91,56 & 100,0 \\
\hline
\end{tabular}

\begin{tabular}{|l|l|l|l|l|l|l|l|l|l|l|l|l|l|l|}
\hline 1,22 & 70,15 & 98,90 & 100,0 & 100,0 & 100,0 & 100,0 & 1,62 & 0,00 & 0,00 & 0,48 & 14,31 & 88,86 & 100,0 \\
\hline
\end{tabular}

\begin{tabular}{|l|l|l|l|l|l|l|l|l|l|l|l|l|l|l|l|}
\hline 1,23 & 63,72 & 98,24 & 99,99 & 100,0 & 100,0 & 100,0 & 1,63 & 0,00 & 0,00 & 0,31 & 11,22 & 85,61 & 100,0 \\
\hline
\end{tabular}

\begin{tabular}{|l|l|l|l|l|l|l|l|l|l|l|l|l|l|l|}
\hline 1,24 & 56,94 & 97,28 & 99,99 & 100,0 & 100,0 & 100,0 & 1,64 & 0,00 & 0,00 & 0,20 & 8,66 & 81,81 & 100,0 \\
\hline
\end{tabular}

\begin{tabular}{|l|l|l|l|l|l|l|l|l|l|l|l|l|l|l|}
\hline 1,25 & 50,00 & 95,92 & 99,98 & 100,0 & 100,0 & 100,0 & 1,65 & 0,00 & 0,00 & 0,13 & 6,57 & 77,46 & 100,0 \\
\hline
\end{tabular}

\begin{tabular}{|l|l|l|l|l|l|l|l|l|l|l|l|l|l|l|l|}
\hline 1,26 & 43,11 & 94,08 & 99,95 & 100,0 & 100,0 & 100,0 & 1,66 & 0,00 & 0,00 & 0,08 & 4,91 & 72,62 & 100,0 \\
\hline
\end{tabular}

\begin{tabular}{|l|l|l|l|l|l|l|l|l|l|l|l|l|l|l|}
\hline 1,27 & 36,48 & 91,66 & 99,91 & 100,0 & 100,0 & 100,0 & 1,67 & 0,00 & 0,00 & 0,05 & 3,61 & 67,35 & 100,0 \\
\hline
\end{tabular}

\begin{tabular}{|l|l|l|l|l|l|l|l|l|l|l|l|l|l|l|}
\hline 1,28 & 30,27 & 88,60 & 99,83 & 100,0 & 100,0 & 100,0 & 1,68 & 0,00 & 0,00 & 0,03 & 2,61 & 61,74 & 100,0 \\
\hline
\end{tabular}

\begin{tabular}{|l|l|l|l|l|l|l|l|l|l|l|l|l|l|l|}
\hline 1,29 & 24,63 & 84,83 & 99,70 & 100,0 & 100,0 & 100,0 & 1,69 & 0,00 & 0,00 & 0,02 & 1,86 & 55,92 & 100,0 \\
\hline
\end{tabular}

\begin{tabular}{|l|l|l|l|l|l|l||l|l|l|l|l|l|l|}
\hline 1,30 & 19,64 & 80,36 & 99,48 & 100,0 & 100,0 & 100,0 & 1,70 & 0,00 & 0,00 & 0,01 & 1,30 & 50,00 & 100,0 \\
\hline
\end{tabular}

\begin{tabular}{|l|l|l|l|l|l|l|l|l|l|l|l|l|l|l|}
\hline 1,31 & 15,35 & 75,21 & 99,14 & 100,0 & 100,0 & 100,0 & 1,71 & 0,00 & 0,00 & 0,01 & 0,90 & 44,12 & 100,0 \\
\hline
\end{tabular}

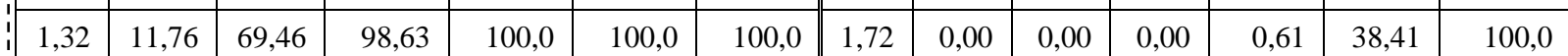

\begin{tabular}{|l|l|l|l|l|l|l|l|l|l|l|l|l|l|l|}
\hline 1,33 & 8,82 & 63,23 & 97,87 & 99,99 & 100,0 & 100,0 & 1,73 & 0,00 & 0,00 & 0,00 & 0,41 & 32,97 & 100,0 \\
\hline
\end{tabular}

\begin{tabular}{|l|l|l|l|l|l|l|l|l|l|l|l|l|l|l|l|}
\hline 1,34 & 6,49 & 56,68 & 96,80 & 99,98 & 100,0 & 100,0 & 1,74 & 0,00 & 0,00 & 0,00 & 0,27 & 27,90 & 100,0 \\
\hline
\end{tabular}

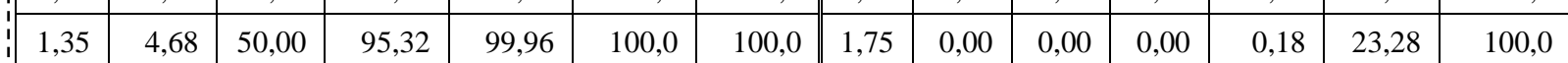

\begin{tabular}{|l|l|l|l|l|l|l|l|l|l|l|l|l|l|l|}
\hline 1,36 & 3,30 & 43,37 & 93,37 & 99,92 & 100,0 & 100,0 & 1,76 & 0,00 & 0,00 & 0,00 & 0,11 & 19,14 & 100,0 \\
\hline
\end{tabular}

\begin{tabular}{|l|l|l|l|l|l|l||l|l|l|l|l|l|l|}
\hline 1,37 & 2,29 & 36,96 & 90,85 & 99,86 & 100,0 & 100,0 & 1,77 & 0,00 & 0,00 & 0,00 & 0,07 & 15,50 & 100,0 \\
\hline
\end{tabular}

\begin{tabular}{|l|l|l|l|l|l|l||l|l|l|l|l|l|l|}
\hline 1,38 & 1,55 & 30,94 & 87,72 & 99,76 & 100,0 & 100,0 & 1,78 & 0,00 & 0,00 & 0,00 & 0,04 & 12,38 & 100,0 \\
\hline
\end{tabular}

\begin{tabular}{|l|r|r|r|r|r|r|r|r|r|r|r|r|r|r|r|r|}
\hline 1,39 & 1,04 & 25,43 & 83,93 & 99,59 & 100,0 & 100,0 & 1,79 & 0,00 & 0,00 & 0,00 & 0,03 & 9,74 & 100,0 \\
\hline
\end{tabular}

\begin{tabular}{|l|l|l|l|l|l|l|l|l|l|l|l|l|l|l|}
\hline 1,40 & 0,68 & 20,52 & 79,48 & 99,32 & 100,0 & 100,0 & 1,80 & 0,00 & 0,00 & 0,00 & 0,02 & 7,55 & 100,0 \\
\hline
\end{tabular}

\begin{tabular}{|l|l|l|l|l|l|l|l|l|l|l|l|l|l|}
\hline 1,41 & 0,43 & 16,25 & 74,41 & 98,92 & 100,0 & 100,0 & 1,81 & 0,00 & 0,00 & 0,00 & 0,01 & 5,77 & 100,0 \\
\hline
\end{tabular}

\begin{tabular}{|l|l|l|l|l|l|l||l|l|l|l|l|l|l|}
\hline 1,42 & 0,27 & 12,63 & 68,80 & 98,32 & 100,0 & 100,0 & 1,82 & 0,00 & 0,00 & 0,00 & 0,01 & 4,34 & 100,0 \\
\hline
\end{tabular}

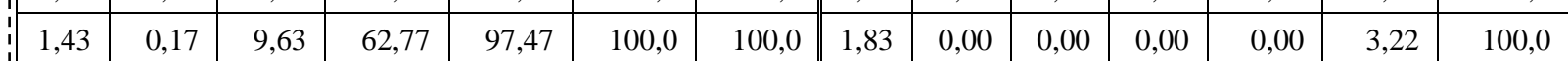

\begin{tabular}{|l|l|l|l|l|l|l|l|l|l|l|l|l|l|}
\hline 1,44 & 0,10 & 7,21 & 56,44 & 96,29 & 100,0 & 100,0 & 1,84 & 0,00 & 0,00 & 0,00 & 0,00 & 2,36 & 100,0 \\
\hline
\end{tabular}

\begin{tabular}{|l|l|l|l|l|l|l|l|l|l|l|l|l|l|l|l|l|}
\hline 1,45 & 0,06 & 5,30 & 50,00 & 94,70 & 100,0 & 100,0 & 1,85 & 0,00 & 0,00 & 0,00 & 0,00 & 1,70 & 100,0 \\
\hline
\end{tabular}

\begin{tabular}{|l|l|l|l|l|l|l|l|l|l|l|l|l|l|l|}
\hline 1,46 & 0,04 & 3,82 & 43,60 & 92,65 & 99,99 & 100,0 & 1,86 & 0,00 & 0,00 & 0,00 & 0,00 & 1,21 & 100,0 \\
\hline
\end{tabular}

\begin{tabular}{|l|l|l|l|l|l|l|l|l|l|l|l|l|l|}
\hline 1,47 & 0,02 & 2,70 & 37,41 & 90,05 & 99,99 & 100,0 & 1,87 & 0,00 & 0,00 & 0,00 & 0,00 & 0,85 & 100,0 \\
\hline
\end{tabular}

\begin{tabular}{|l|l|l|l|l|l|l|l|l|l|l|l|l|l|}
\hline 1,48 & 0,01 & 1,88 & 31,57 & 86,86 & 99,98 & 100,0 & 1,88 & 0,00 & 0,00 & 0,00 & 0,00 & 0,59 & 100,0 \\
\hline
\end{tabular}

\begin{tabular}{|l|l|l|l|l|l|l||l|l|l|l|l|l|l|}
\hline 1,49 & 0,01 & 1,28 & 26,19 & 83,05 & 99,96 & 100,0 & 1,89 & 0,00 & 0,00 & 0,00 & 0,00 & 0,40 & 100,0 \\
\hline
\end{tabular}

\begin{tabular}{|l|l|l|l|l|l|l|l|l|l|l|l|l|l|l|l|}
\hline 1,50 & 0,00 & 0,86 & 21,36 & 78,64 & 99,93 & 100,0 & 1,90 & 0,00 & 0,00 & 0,00 & 0,00 & 0,27 & 100,0 \\
\hline 1,51 & 0,00 & 0,57 & 17,12 & 73,67 & 99,87 & 100,0 & 1,91 & 0,00 & 0,00 & 0,00 & 0,00 & 0,18 & 100,0 \\
\hline
\end{tabular}

\begin{tabular}{|l|l|l|l|l|l|l|l|l|l|l|l|r|r|r|}
\hline 1,52 & 0,00 & 0,37 & 13,48 & 68,19 & 99,77 & 100,0 & 1,92 & 0,00 & 0,00 & 0,00 & 0,00 & 0,12 & 99,99 \\
\hline
\end{tabular}

\begin{tabular}{|l|l|l|l|l|l|l|l|l|l|l|l|l|l|}
\hline 1,53 & 0,00 & 0,23 & 10,43 & 62,34 & 99,62 & 100,0 & 1,93 & 0,00 & 0,00 & 0,00 & 0,00 & 0,08 & 99,99 \\
\hline
\end{tabular}

\begin{tabular}{|r|r|r|r|r|r|r|r|r|r|r|r|r|r|r|r|r|}
\hline 1,54 & 0,00 & 0,15 & 7,93 & 56,22 & 99,39 & 100,0 & 1,94 & 0,00 & 0,00 & 0,00 & 0,00 & 0,05 & 99,98 \\
\hline
\end{tabular}

\begin{tabular}{|l|l|l|l|l|l|l|l|l|l|l|l|l|r|r|}
\hline 1,55 & 0,00 & 0,09 & 5,93 & 50,00 & 99,04 & 100,0 & 1,95 & 0,00 & 0,00 & 0,00 & 0,00 & 0,03 & 99,97 \\
\hline
\end{tabular}

\begin{tabular}{|l|l|l|l|l|l|l|l|l|l|l|l|l|l|l|}
\hline 1,56 & 0,00 & 0,05 & 4,36 & 43,82 & 98,53 & 100,0 & 1,96 & 0,00 & 0,00 & 0,00 & 0,00 & 0,02 & 99,95 \\
\hline
\end{tabular}

\begin{tabular}{|l|l|l|l|l|l|l|l|l|l|l|l|l|l|}
\hline, 56 & 0,00 & 0,05 & 4,36 & 43,82 & 98,53 & 100,0 & 1,96 & 0,00 & 0,00 & 0,00 & 0,00 & 0,02 & 99,95 \\
\hline 1,57 & 0,00 & 0,03 & 3,14 & 37,83 & 97,80 & 100,0 & 1,97 & 0,00 & 0,00 & 0,00 & 0,00 & 0,01 & 99,91 \\
\hline
\end{tabular}

\begin{tabular}{|l|l|l|l|l|l|l|l|l|l|l|l|l|l|l|l|l|l|}
\hline 1,58 & 0,00 & 0,02 & 2,23 & 32,15 & 96,81 & 100,0 & 1,98 & 0,00 & 0,00 & 0,00 & 0,00 & 0,01 & 99,86 \\
\hline
\end{tabular}

\begin{tabular}{|l|l|l|l|l|l|l|l|l|l|l|l|l|l|l|l|}
\hline 1,59 & 0,00 & 0,02 & 2,23 & 32,15 & 96,81 & 100,0 & 1,98 & 0,00 & 0,00 & 0,00 & 0,00 & 0,01 & 99,86 \\
\hline
\end{tabular}


могут быть рекомендованы для расчета технологических показателей обогащения полезных ископаемых.

\section{СКВП}

Расчет извлечения фракций в продукты обогащения тяжелосредного сепаратора

Определение извлечения фракций, $E$, в продукты обогащения при моделировании процессов разделения каменных углей и антрацитов в тяжелосредных сепараторах выполняется по формуле

$$
E=100 \Phi(x)
$$

Рассчитанные извлечения фракций в концентрат и отходы тяжелосредного сепаратора СКВП для плотностей разделения от 1.20 до 1.99 с шагом 0.01 и средних плотностей фракций $1.25,1.35,1.45,1.55,1.79,2.20$ показаны в таблицах $4 a$ и $4 b$.

Результаты расчетов, показанные в таблице 4, можно использовать в практических расчетах ожидаемых результатов обогащения в тяжелосредных сепараторах согласно методике [8] и ВНТП 3-92, не прибегая к табличным значениям интеграла Гаусса.

Таким образом, из приведенного материала можно сделать следующие выводы:

1. Проанализирован российский и международный опыт обогащения антрацитов различных месторождений, отмечены особенности технологических схем пяти обогатительных фабрик в зависимости от характеристик поступающего на обогащение антрацита.

2. Обозначены технологические схемы с максимальным извлечением горючей массы в готовую продукцию и схемы с получением максимальных потребительских свойств в концентрате, что, несомненно, сказывается и на себестоимости процесса обогащения в целом.

3. Рассмотрены вероятностные методы определения эффективности разделения углей и антрацитов крупных классов 13-100 (150) мм в тяжелосредных сепараторах, предложено практическое их применение в виде рассчитанных на ЭВМ извлечений фракций в концентрат и отходы тяжелосредного сепаратора СКВП.

4. Результаты исследований возможно учитывать в инженерных расчетах схем гравитационного обогащения при проектировании новых фабрик по обогащению каменных углей и антрацитов, а также техническом перевооружении действующих производств.

\section{СПИСОК ЛИТЕРАТУРЫ}

1. Геология. Наука о вечно меняющейся Земле/ А. Аллисон, Д. Палмер; Под ред. Ю.Г. Леонова. М.: Мир, 1984. $-568 \mathrm{c}$.

2. Геомеханика открытых горных работ/ А.М. Гальперин.- М.: МГГУ, 2003. - 473c.

3. Отчет о научно-исследовательской работе «Изучение метаморфизированных углей Красногорского разреза и оценка возможных областей использования их в промышленности», выполненный Институтом минералогии и петрографии (ИМП) г. Новосибирск 1995 год

4. Техника и технология обогащения углей. Справочное руководство/ В.В. Беловолов, Ю.Н. Бочков, М.В. Давыдов и др.; Под ред. В.А. Чантурия.- М.: Наука, 1995.- 622c.

5. https://dic.academic.ru/dic.nsf/bse/64401/Антрацит (дата обращения: 30.03.2018).

6. www.sibanthracite.ru/ (дата обращения: 30.03.2018).

7. www.sibanthracite.ru/product/ (дата обращения: 30.03.2018).

8. Артюшин С.П. Проектирование углеобогатительных фабрик: Изд. 2-е, перераб. и доп. / С.П. Артюшин. - М.: Недра, 1974. - 200 с.

9. Удовицкий В.И. Моделирование подготовительных и основных процессов переработки каменных углей / В.И. Удовицкий. - Кемерово : Кузбассвузиздат, 1998. - 500 с.

10. https://ru.wikipedia.org/wiki/Антрацит (дата обращения: 29.07.2018).

11. http://fb.ru/article/175119/antratsit-ugol-kamennyiy-harakteristiki-i-mesta-dobyichi (дата обращения: 29.07.2018)

12. http://www.mining-enc.ru/a/antracit (дата обращения: 29.07.2018) $54 \mathrm{c}$.

13. Кирнарский А.С. Обогащение антрацита на фабрике Иббенбюрен. Журнал - Уголь 7-2012. $53-$ 
14. Популях А.Д., Еремеев И.В. Особенности обогащения рядового антрацита на ЦОФ «Гуковская». Журнал - Уголь Украины 1-2014. 41-44с.

15. Удовицкий В.И., Шутов С.О., Королев И.А., Кандинский В.А.Экономико-математическое моделирование процессов и технологий обогащения полезных ископаемых. Электронное учеб. пособие /Кузбас. гос. техн. ун-т, Кемерово, 2012.

16. Удовицкий В.И., Королев И.А., Шутов С.О., Кандинский В.А.Информационное обеспечение методов моделирования технологий тяжелосредного обогащения каменных углей. В сборнике:// Фундаментальные и прикладные проблемы в горном деле: Материалы всероссийской научнопрактической конференции. Междуреченск, 25 февраля 2016 г. С. 77-82.

17. Удовицкий В.И., Кандинский В.А., Бегунов А.А., Плотникова Л.Н. Моделирование процессов и технологий обогатительной фабрики "Распадская" для оценки влияния усреднения угля на технологические показатели продуктов обогащения. E3S Web of Conferences Volume 134, 28 ноября 2019 года.

18. Популях А.Д., Корчевский А.Н., Еремеев И.В. Складирование жидких отходов углеобогатительных фабрик в породных отвалах. Журнал - Уголь Украины 6-2015. 48-51с.

\section{REFERENCES}

1. Geology. Science of the ever-changing Earth/ A. Allison, D. Palmer; edited by Y.G. Leonov. - Moscow: Mir, 1984. - 568p.

2. Geomechanics of open-pit mining / A.M. Galperin. - M.: MGGU, 2003. - 473p.

3. Report on the research work "Study of metamorphosed coals of the Krasnogorsk section and assessment of possible areas of their use in industry", carried out by the Institute of Mineralogy and petrography (IMP), Novosibirsk 1995

4. Technique and technology of coal enrichment. Reference guide/ V.V. Belovolov, Y.N. Bochkov, M.V. Davydov et al.; Moscow: Nauka, 1995. -622p.

5. https://dic.academic.ru/dic.nsf/bse/64401/Антрацит (accessed: 30.03.2018).

6. www.sibanthracite.ru/ (accessed: 30.03.2018).

7. www.sibanthracite.ru/product/ (accessed: 30.03.2018).

8. Artyushin S.P. Design of coal-processing factories: 2nd Ed., revised and expanded/ S.P. Artyushin. - M.: Nedra, 1974. - 200 p.

9. Udovitsky V.I. Modeling of preparatory and basic processes of processing of coal / V.I. Udovitsky. Kemerovo: Kuzbassvuzizdat, 1998. - 500 p.

10. https://ru.wikipedia.org/wiki/Антрацит (accessed: 29.07.2018).

11. http://fb.ru/article/175119/antratsit-ugol-kamennyiy-harakteristiki-i-mesta-dobyichi (accessed: 29.07.2018)

12. http://www.mining-enc.ru/a/antracit (accessed: 29.07.2018)

13. Kirnarsky A. S. Anthracite enrichment at the Ibbenburen factory. Journal of Coal 7-2012. 53-54 p.

14. Populakh A.D., Eremeev I. V. Features of the enrichment of ordinary anthracite at the Gukovskaya Central Processing Plant. Magazine-Coal of Ukraine 1-2014. 41-44c.

15. Udovitsky V.I., Shutov S.O., Korolev I.A., Kandinsky V.A. Economic and mathematical modeling of processes and technologies of mineral processing. E-learning. manual /Kuzbass. state Technical University. un-t, Kemerovo, 2012.

16. Udovitsky V.I., Korolev I.A., Shutov S.O., Kandinsky V.A. Information support of methods of modeling technologies of heavy-medium coal enrichment. In the collection:// Fundamental and applied problems in mining: Materials of the All-Russian scientific and practical conference. Mezhdurechensk, February 25, 2016, pp. 77-82.

17. Udovitsky V.I., Kandinsky V.A., Begunov A.A., Plotnikova L.N. Modeling of processes and technologies of the concentrating Raspadskaya factory for assessing the impact of dilution of raw coal on the technological performance of enrichment products.E3S Web of ConferencesVolume 134, 28 November 2019.

18. Populakh A.D., Korchevskyi A.N., Eremeev I. V. Storage of liquid waste from coal processing plants in rock dumps. Magazine-Coal of Ukraine 6-2015. 48-51c.

\section{Библиографическое описание статьи} Удовицкий В.И., Кирнарский А.С., Корчевский A.Н., Бегунов А.А., Кандинский В.А., Плотникова Л.Н. Антрацит. Сравнение технологий обогащения. методы оценки эффективности разделения углей и антрацитов в гравитационных аппаратах с тяжелой средой // Вестник Кузбасского государственного технического университета. - 2021. - № 4 (146). - C. 49-65.

\section{Reference to article}

Udovitsky V.I., Kirnarski A.S., Korchevskyi A.N., Begunov A.A., Kandinsky V.A., Plotnikova L.N. Anthracite. Comparison of enrichment technologies. methods for evaluating the efficiency of separation of coals and anthracites in gravity apparatuses with heavy media. Bulletin of the Kuzbass State Technical University, 2021, no.4 (146), pp. 49-65 